\title{
V18 - ESTUdO DE CONDIÇÕES PASSÍVEIS DE AMPLIAÇÃO DE ESCALA PARA PROPAGAÇÃO DE CÉLULAS VERO EM MICROCARREGADORES
}

\author{
Aline Guimarães de Almeida, ${ }^{1,3}$, Rodrigo Coelho Ventura Pinto ${ }^{2}$, Marta Cristina de \\ Oliveira Souza ${ }^{1}$, Luciane Pinto Gaspar ${ }^{1}$, Elena Caride Siqueira Campos ${ }^{1}$, Sheila Maria \\ Barbosa de Lima ${ }^{1}$, Anna Maya Yamamura ${ }^{1}$
}

1- Vice-Diretoria de Desenvolvimento Tecnológico, Bio-Manguinhos, FIOCRUZ

2- Vice-Diretoria de Produção, Bio-Manguinhos, FIOCRUZ

3 - Universidade Federal do Rio de Janeiro, COPPE, Rio de Janeiro, Brasil

Objetivo: Devido à necessidade crescente de desenvolvimento de bioprocessos para produção de vacinas virais empregando linhagens de células de mamíferos, bem como a proposta de uma nova metodologia para a produção de uma vacina inativada contra a febre amarela baseado na propagação do vírus amarílico em biorreatores sob condições monitoradas e controladas, utilizando microcarregadores, o estudo do escalonamento desses processos torna-se de grande relevância. Uma parte fundamental dessa ampliação de escada é a multiplicação celular. No caso de células aderentes cultivadas em biorreatores agitados, as alternativas para obtenção de inóculo celular em quantidade suficiente que possa ser reproduzido em escala industrial é um desafio. Neste trabalho estudou-se diferentes condições, passíveis de ampliação de escala, da propagação de células Vero em sistema agitado, utilizando microcarregadores.

Metodologia: Diferentes técnicas para transferência de células foram investigadas. Para estudar a transferência bead-to-bead foi proposto um planejamento experimental fatorial completo $2^{2}$ onde a agitação contínua ou intermitente, bem como o intervalo de agitação e intermitência foram variados. O crescimento celular foi avaliado pela contagem dos núcleos celulares corados com cristal violeta e a concentração de glicose e lactato presente no sobrenadante avaliada utilizando-se analisador bioquímico marca YSI. Uma avaliação visual da confluência dos microcarregadores foi feita por microscopia óptica invertida. A tripsinização das células aderidas aos microcarregadores também foi estudada, acrescentando um tratamento prévio do meio de cultivo com $\mathrm{NaOH}$, alcalinizando-o até que atingisse um $\mathrm{pH}$ entre $8-9$. 
Resultados: Das condições experimentais propostas no planejamento experimental, verificou-se que apenas na condição experimental 2 (60 minutos de repouso/15 minutos de agitação) ocorreu a transferência bead-to-bead, com um posterior crescimento celular significativo, e constatação de pontes de células entre os microcarregadores. Independente das concentrações de tripsina testadas, observou-se que apesar das células apresentaram capacidade de aderir novamente aos microcarregadores, não houve proliferação significativa. No entanto, ao se alcalinizar o meio de cultivo antes da tripsinização, além se obter um processo eficaz, as células demonstraram capacidade de aderir novamente aos microcarregadores e também de se multiplicar nos mesmos.

Conclusões: Nos ensaios de transferência bead-to-bead somente na condição 2 do planejamento experimental ocorreu a transferência de células entre microcarregadores e subsequente proliferação. Já empregando a metodologia de tripsinização, observou-se que a manutenção de um pH ideal para a atividade da enzima é crítico para o processo. 